\title{
Prognostic value of left atrial volume index in acute coronary syndrome: A systematic review and meta-analysis
}

\author{
Artan Ahmeti $^{1,2}$ | Feriz S. Bytyçi ${ }^{3}$ | Agata Bielecka-Dabrowa ${ }^{4}$ | Ibadete Bytyçi, ${ }^{1,5}$ (D) | \\ Michael Y. Henein ${ }^{5,6,7}$
}

${ }^{1}$ Clinic of Cardiology, University Clinical Centre of Kosovo, Prishtina, Kosovo

${ }^{2}$ Medical Faculty, University of Prishtina, Prishtina, Kosovo

${ }^{3}$ Main Family Medical Center, Prishtina, Kosovo

${ }^{4}$ Department of Hypertension, Medical University of Lodz, Lodz, Poland

${ }^{5}$ Institute of Public Health and Clinical Medicine, Umeå University, Umeå, Sweden

${ }^{6}$ Molecular and Clinic Research Institute, St George University, London, UK

${ }^{7}$ Brunel University, London, UK

\section{Correspondence}

Ibadete Bytyçi, Clinic of Cardiology, University Clinical Centre of Kosovo, Prishtina, Kosovo

Email: i.bytyci@hotmail.com

\begin{abstract}
Background: In the absence of mitral valve disease, increased left atrial volume (LAV) is a marker of diastolic dysfunction and long-standing elevated left ventricle (LV) pressure. The aim of this study was to assess the role of increased baseline LAV in predicting clinical outcome of patients presenting with acute coronary syndrome (ACS).

Methods: We systematically searched all electronic databases up to September 2020 in order to select clinical trials and observational studies, which assessed the predictive role of LAV indexed (LAVI) on clinical outcome in patients with ACS. Primary clinical endpoints were as follows: major adverse cardiac events (MACE), all-cause mortality and hospitalization. Secondary endpoints were in-hospital complications.
\end{abstract}

Results: A total of 2,705 patients from 11 cohort studies with a mean follow-up $18.7 \pm 9.8$ months were included in the metaanalysis. Patients with low LAVI had low risk for MACE (15.9\% vs. $33.7 \% ; p<.01)$, long-term all-cause mortality $(9.14 \%$ vs. $18.1 \% ; p<.01)$, short-term mortality (3.31\% vs. $9.38 \% ; p=.02$ ) and lower hospitalization rate $(11.6 \%$ vs. $25.5 \% ; p<.01)$ compared to patients with increased LAVI. Atrial fibrillation and cardiogenic shock as in-hospital events were lower $(p<.05$ for all) in patients with low LAVI but ventricular fibrillation/tachycardia was not different between groups $(p=.14)$.

Conclusion: Increased LAVI is an independent predictor of outcome in patients with ACS. Thus, assessment of LA index in these patients is important for better risk stratification and guidance towards optimum clinical management.

\section{KEYWORDS}

acute coronary syndrome, clinical outcome, left atrial volume

This is an open access article under the terms of the Creative Commons Attribution-NonCommercial-NoDerivs License, which permits use and distribution in any medium, provided the original work is properly cited, the use is non-commercial and no modifications or adaptations are made. 


\section{1 | INTRODUCTION}

Increased left atrial (LA) size is associated with raised left ventricular filling (LV) pressure and poor clinical outcome, particularly in patients with heart failure (HF) due to diastolic dysfunction (Dokainish et al., 2005). LA volume has been proposed as the best measure of LA enlargement compared with the simple antero-posterior diameter, hence has become the recommended method for measuring LA size by echocardiography (Abhayaratna et al., (2006)). LA volume indexed to body surface area (LAVI) has been suggested as a marker for severity and duration of diastolic dysfunction (DD) as well as a predictor of related clinical events such as atrial fibrillation, congestive heart failure, and embolic stroke (Tsang et al., 2002). Arterial hypertension, ventricular hypertrophy and other cardiovascular disorders (CV) are associated with left ventricular diastolic dysfunction (LVDD), raised filling pressures and atrial remodelling due to chronic pressure overload (Bytyçi \& Bajraktari, 2016).

In patients with acute coronary syndrome (ACS), left ventricular ejection fraction (LVEF) (Moss, 1984), the ratio of peak early-to-late LV filling velocities (E/A), E-wave deceleration time (DcT; Nijland et al., 1997; Sestili et al., 2007) and the ratio of early diastolic LV filling velocity to that of mitral annular velocity (E/e'Alam et al., 2007; Hillis et al., 2004) have been shown to be good prognostic echocardiographic markers. LAVI at hospital admission has also been reported as an indicator of the prognosis, with values of $32 \mathrm{ml} / \mathrm{m}^{2}$ or more associated with poor prognosis ( Gunasekaran et al., 2012; Patel et al., 2011). The aim of this study was to meta-analyse the existing evidence about the prognostic value of LA volume in predicting clinical outcome in patients presenting with ACS.

\section{2 | METHODS}

We followed the 2009 guidelines preferred reporting items for systematic reviews and meta-analysis (PRISMA) statement (Moher et al., 2009), amendment to the Quality of Reporting of Metaanalyses statement (Higgins \& Green, 2009). Due to the study design (meta-analysis), neither Institutional Review Board approval nor patient informed consent was needed.

\section{1 | Search strategy}

We systematically searched PubMed, Medline, EMBASE, Scopus, Google Scholar and the Cochrane Central Registry, up to September 2020 in order to select clinical trials and observational studies, which assessed the predictive role of LAVI for clinical outcome in patients with ACS, using the following keywords: "Left atrial volume index" OR "LAVI" AND "Acute coronary syndrome" OR "ACS" OR "Acute myocardial infarction" OR "AMI" OR "ST elevation myocardial infarction" OR "Non ST elevation myocardial infarction" AND "Clinical outcomes". Additional searches for potential trials included the references of review articles on that issue, and the abstracts from selected congresses: scientific sessions of the European Society of Cardiology (ESC), the American Heart Association (AHA), American College of Cardiology (ACC) and European Association of Cardiovascular Imaging (EACVI). The wild-card term "*" was used to increase the sensitivity of the search strategy. The literature search was limited to studies in humans which was written in English. Two reviewers (A.A. and F.S.B.) independently evaluated each article, and no filters were applied.

\section{2 | Study selection}

Inclusion criteria were as follows: (a) studies investigated ACS patients with measurements of LAVI, (b) reporting LAVI cut-off value of (32 or $34 \mathrm{ml} / \mathrm{m}^{2}$ ), (c) reporting short- and/or long-term outcome, (d) follow-up and (e) enrolled population of adults aged $\geq 18$ years, and (f) only studies in English.

Exclusion criteria were as follows: (a) no report based on LAVI cut-off, (b) insufficient statistical data to compare two groups, (c) no follow-up, (d) studies not in humans and (e) studies not in English.

\section{3 | Outcome variables}

Primary clinical endpoints were as follows: major adverse cardiac events (MACE), long-term all-cause mortality (during follow-up), short-term all-cause mortality (within 30 days after hospital admission) and hospitalization. Secondary endpoints were in-hospital complications such as ventricular fibrillation (VF), ventricular tachycardia (VT), atrial fibrillation (AF) and cardiogenic shock, long-term (during follow-up) all-cause mortality and short-term (within 30 days of procedure) all-cause mortality.

\section{4 | Data extraction}

Eligible studies were reviewed, and the following data were abstracted: (a) first author's name; (b) year of publication; (c) study design; (d) data on two arms: low and increased LAVI; (e) patients' baseline characteristics; (f) mean follow-up period; and (g) age and gender of participants.

\section{5 | Quality assessment}

Assessment of risk of bias in cohort studies we used the NewcastleOttawa Scale (NOS). The risk of bias in each study was judged to be "good," "fair" or "poor"(Zeng et al., 2015).

\subsection{Statistical analysis}

The meta-analysis was conducted using statistical analysis, performed using the RevMan (Review Manager [RevMan] version 5.1, 


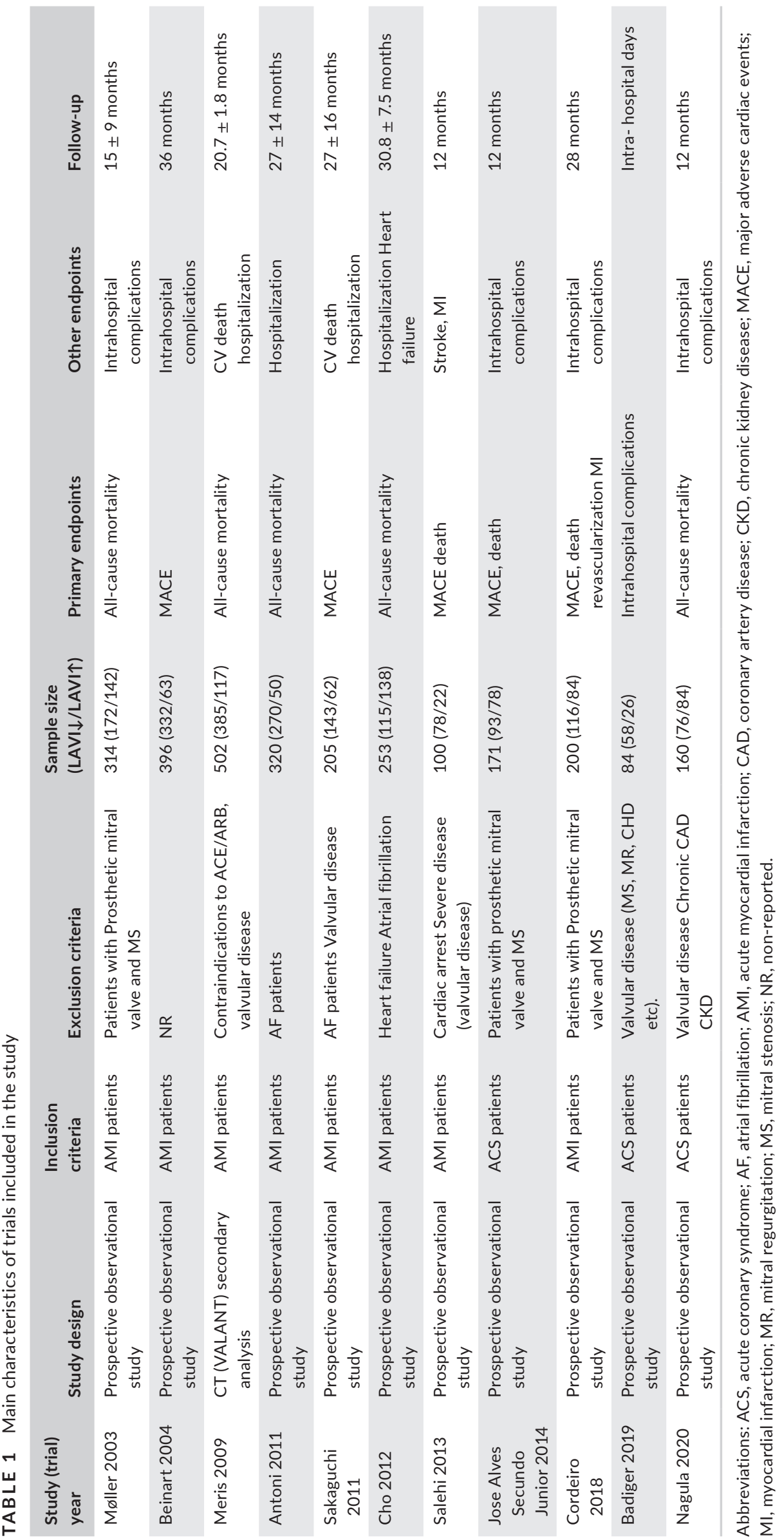


The Cochrane Collaboration, Copenhagen, Denmark), with two-tailed $p<.05$ considered as significant. Relative risk (RR) ratios with $95 \%$ confidence interval $(\mathrm{Cl})$ are presented as summary statistics, whereas for continuous variable weighted mean differences (WMD) and $95 \%$ $\mathrm{Cl}$ were used. The baseline characteristics are reported in mean and standard deviation (SD) which were estimated using the method described by Hozo et al. (2005). Analysis is presented in forest plots, the standard way for illustrating the results of individual studies and metaanalysis. The meta-analyses were performed with the random-effects model. Heterogeneity between studies was evaluated using Cochrane $Q$ test and $I^{2}$ index. As a guide, $I^{2}<25 \%$ indicated low, 25\%-50\% moderate and $>50 \%$ high heterogeneity (Morton et al., 2004). To assess the additive (between-study) component of variance, the reduced maximum likelihood method $\left(\tau^{2}\right)$ incorporated the occurrence of residual heterogeneity into the analysis (Higgins et al., 2003). Publication bias was assessed using visual inspections of funnel plots and Egger's test.

\section{RESULTS}

\subsection{Search results and trial flow}

Of 3,184 articles identified in the initial searches, 261 studies were considered as potentially relevant. After stringent selection process, 11 articles met the inclusion criteria (Antoni et al., 2011; Badiger, 2019; Beinart et al., 2004; Cho et al., 2012; Cordeiro et al., 2018; Meris et al., 2009; Moller et al., 2003; Nagula et al., 2020; Sakaguchi et al., 2011; Salehi et al., 2013; Secundo Junior et al., 2014): one was secondary analysis of CTs (Antoni et al., 2011), and remaining 10 papers were observational studies. (Figure S1).

\subsection{Characteristics of included studies}

Eleven studies with a total of 2,705 patients (1,819 with low LAVI and 886 with high LAVI), with mean follow-up duration of $18.7 \pm 9.8$ months, were included (Table 1). The two groups of patients had similar age ( $62.3 \pm 7.8$ vs. $60.4 \pm 6.9$ years, $p=.21)$ and female gender distribution $(29.2 \%$ vs. $34.1 \% p=.13)$. No difference was found between the two groups with regard to cardiovascular risk factors including smoking ( $45.4 \%$ vs. $42.8 \% p=.27)$ and dyslipidaemia (39.7\% vs. $42.5 \% p=.34$ ) but patients with high LAVI had more prevalent hypertension $(62.4 \%$ vs. $51.7 \% p=.01)$, diabetes (33.9\% vs. $27.05 \% p=.02)$, previous MI (25.1\% vs. $17.6 \% p=.02)$, previous $\mathrm{PCl}(26.3 \%$ vs. $13.7 \% p<.01)$ and CABG $(4.1 \%$ vs. $2.5 \%$ $p<.01)$ compared to those with low LAVI (Table S1).

\section{3 | Baseline LV and LA structure and function in the two groups of patients}

Patients with low LAVI had smaller LV dimensions: LV end-diastolic dimension (LVEDD) with WMD $-2.25(95 \% \mathrm{Cl},-3.33$ to -1.26 , $p<.001)$, LV end-systolic dimension (LVESD) WMD $-6 \mathrm{~cm}(95 \%$ $\mathrm{Cl},-11$ to $-0.10, p=.04)$ and higher LV EF with WMD $5.02(95 \%$ $\mathrm{Cl}, 3.25-6.80, p<.001)$. In the same group of patients, LV diastolic function was less compromised having lower E/e' ratio WMD -1.48 (95\% Cl, -2.21 to $-0.75, p<.001$ ) compared to patients with high LAVI (Figure S2). The same group of patients with low LAVI had less prevalent moderate to severe mitral regurgitation (6.46\% vs. $27.1 \%$; $p<.001)$, less prevalent multivessel coronary disease $(53.8 \%$ vs. $60.6 \% ; p=.04)$, less prevalent concomitant atrial fibrillation $(4.16 \%$ vs. $8.1 \% ; p=.04$ ) and less patients with Killip class $\geq 2$ compared to those with high LAVI. Wall motion score index (WMS) was not different between the two groups of patients ( $p=.61$, Figure S3).

\subsection{Clinical outcome in the two patient groups}

Patients with low LAVI had lower risk for MACE (15.9\% vs. 33.7\%; $\mathrm{RR}=0.36,95 \% \mathrm{Cl}: 0.27$ to $0.47, p<.01, \mathrm{I}^{2}=46 \%$ ), long-term allcause mortality $(9.14 \%$ vs. $18.1 \%$; $R R=0.33,95 \% \mathrm{Cl}: 0.23$ to 0.47 , $p<.01, I^{2}=33 \%$ ), short-term all-cause mortality (3.31\% vs. $9.38 \%$; $\mathrm{RR}=0.30,95 \% \mathrm{Cl}: 0.11$ to $\left.0.85, p=.02, I^{2}=22 \%\right)$ and lower hospitalization rate $(11.6 \%$ vs. $25.5 \%$; $R R=0.35,95 \% \mathrm{Cl}: 0.19$ to 0.64 , $p<.01, I^{2}=66 \%$ ) compared to patients with high LAVI (Figure 1).

\section{5 | In-hospital events in the two groups of patients}

The occurrence of atrial fibrillation $(4.16 \%$ vs. $8.17 \%, p=.04)$ and cardiogenic shock $(2.86 \%$ vs. $11.5 \%, p<.01)$ was significantly less in patients with low LAVI compared to those with high LAVI, but there was no difference in the prevalence of ventricular fibrillation/tachycardia (11.8\% vs. $10.9 \%, p=.14$, Figure 2 ) between the two groups.

\subsection{Risk of bias assessment}

Many of the observational studies have good quality; below $25 \%$ of them have fair quality (Table S2). Also, there was no evidence for publication bias as evaluated by the Egger's test for our findings.

\section{DISCUSSION}

\subsection{Findings}

The results of meta-analysing the available evidence for the clinical significance of the LAVI in ACS patients may be summarized as follow: (a) patients with low LAVI had less prevalent moderate to severe mitral regurgitation, less Killip class $\geq 2$, less multivessel disease and better LV systolic and diastolic function compared to those with high LAVI; (b) Patients with low LAVI had lower risk of MACE, longand short-term all-cause mortality and lower hospitalization rate 
(a) MACE

\begin{tabular}{|c|c|c|c|c|c|c|c|c|c|c|}
\hline \multirow[b]{2}{*}{ Study or Subgroup } & \multicolumn{2}{|c|}{$\mathrm{LAVI} \leq 32 \mathrm{ml} / \mathrm{m} 2$} & \multicolumn{2}{|c|}{$\mathrm{LAVI}>32 \mathrm{ml} / \mathrm{m} 2$} & \multicolumn{3}{|c|}{ Risk Ratio } & \multirow{2}{*}{\multicolumn{3}{|c|}{$\begin{array}{c}\text { Risk Ratio } \\
\text { M-H, Random, } 95 \% \mathrm{Cl}\end{array}$}} \\
\hline & Events & Total & Events & Total & Weight & M-H, Random, 95\% Cl & Year & & & \\
\hline Meris 2009 & 119 & 481 & 45 & 85 & $24 \cdot 7 \%$ & $0.47[0.36,0.60]$ & 2009 & $\longrightarrow$ & & \\
\hline Antoni 2011 & 38 & 270 & 17 & 50 & $16.0 \%$ & $0.41[0.25,0.67]$ & 2011 & & & \\
\hline Sakaguchi 2011 & 9 & 143 & 20 & 62 & $10 \cdot 0 \%$ & $0.20[0.09,0.40]$ & 2011 & $\leftarrow$ & & \\
\hline Cho 2012 & 3 & 115 & 27 & 138 & $4 \cdot 9 \%$ & $0.13[0.04,0.43]$ & 2012 & $\longmapsto$ & & \\
\hline Secundo Junior JA 2014 & 7 & 93 & 20 & 78 & $8 \cdot 7 \%$ & $0.29[0.13,0.66]$ & 2014 & $\longleftarrow$ & & \\
\hline Cordeiro 2018 & 23 & 116 & 35 & 84 & $17 \cdot 4 \%$ & $0.48[0.30,0.74]$ & 2018 & & & \\
\hline Badiger 2019 & 9 & 58 & 9 & 26 & $8.8 \%$ & $0.45[0.20,1.00]$ & 2019 & & & \\
\hline Nagula 2020 & 7 & 76 & 32 & 84 & $9 \cdot 5 \%$ & $0.24[0.11,0.52]$ & 2020 & & & \\
\hline Total (95\% Cl) & & 1352 & & 607 & $100 \cdot 0 \%$ & $0.36[0.27,0.47]$ & & & & \\
\hline Total events & 215 & & 205 & & & & & & & \\
\hline \multicolumn{8}{|c|}{$\begin{array}{l}\text { Heterogeneity: } \mathrm{Tau}^{2}=0.07 ; \mathrm{Chi}^{2}=12.89, \mathrm{df}=7(\mathrm{P}=0.07) ; \mathrm{I}^{2}=46 \% \\
\text { Test for overall effect: } \mathrm{Z}=7 \cdot 21(\mathrm{P}<0.00001)\end{array}$} & $\begin{array}{c}0.5 \\
\text { Favours lo }\end{array}$ & $I_{1}^{1}$ Favours hi & 5 \\
\hline
\end{tabular}

(b) Long-term all-cause mortality

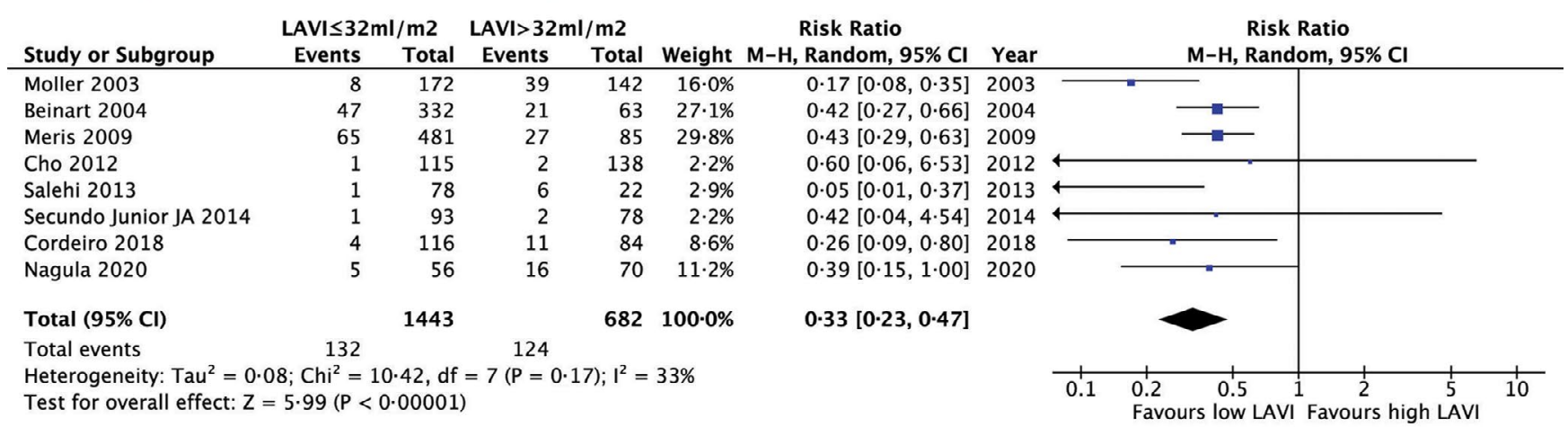

(c) Short-term all-cause mortality

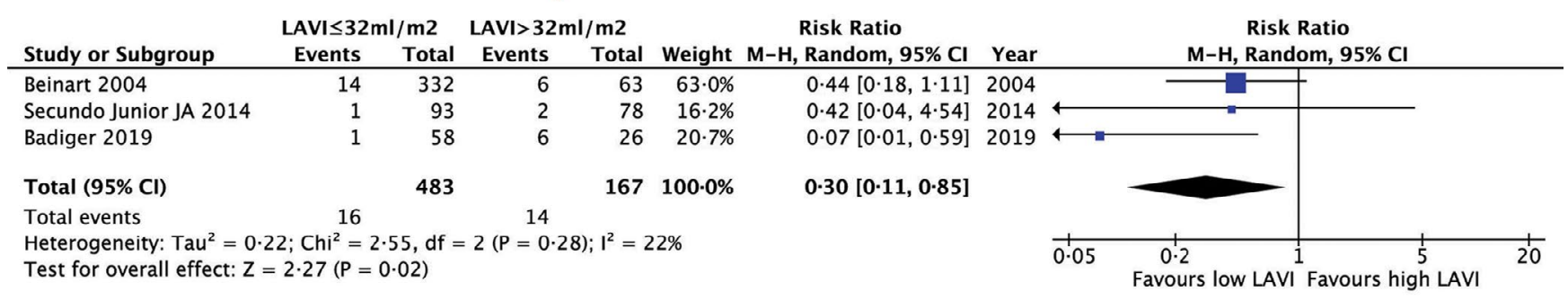

\section{(d) Hospitalization}

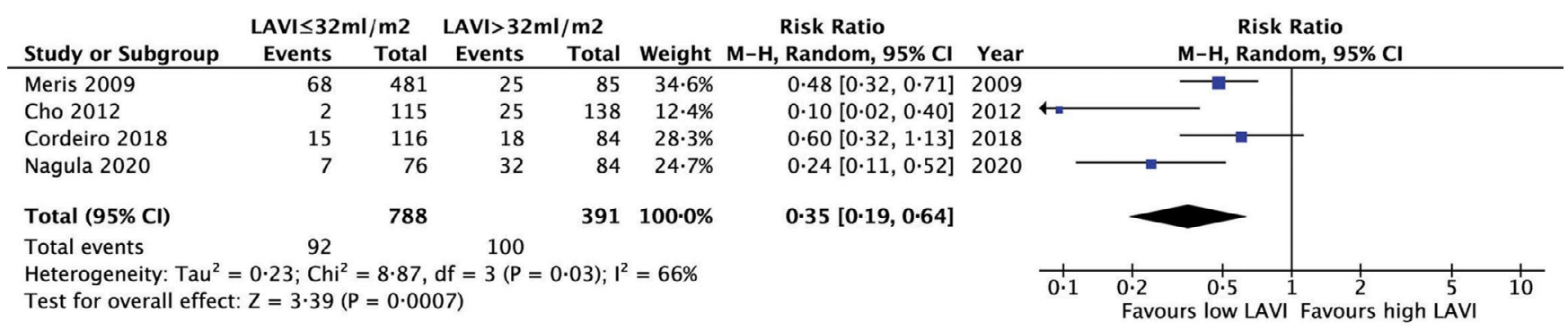

FIGURE 1 Risk ratios of clinical outcome in two groups of patients; (a) MACE; (b) Long-term all-cause mortality; (c) Short-term all-cause mortality; (d) Hospitalization

compared to those with high LAVI; and (c) Patients with high LAVI had worse prognosis regarding in-hospital clinical complications.

\section{2 | Data interpretation}

In the absence of significant mitral valve disease, increased LAVI is usually a surrogate for elevated LV end-diastolic pressure (LVEDP), worsening of LV diastolic dysfunction and raised cavity stiffness (Basnight et al., 1991). During ventricular diastole, the LA is directly exposed to diastolic LV pressure through the open mitral valve; hence, raised diastolic pressures are propagated to the LA and raise its cavity pressure. In view of the significantly thinner wall of the left atrium compared to the left ventricle, the myocardium of the former stretches in response to the increased pressure and the cavity enlarges. Such changes impact LA cavity in its ability to accommodate 


\section{(a) $\mathbf{V T} / \mathrm{VF}$}

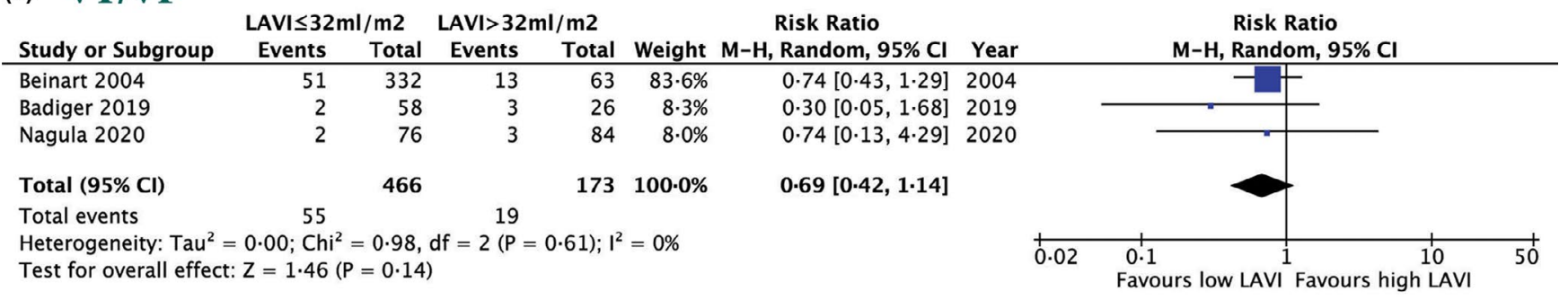

(b) $\mathbf{A F}$

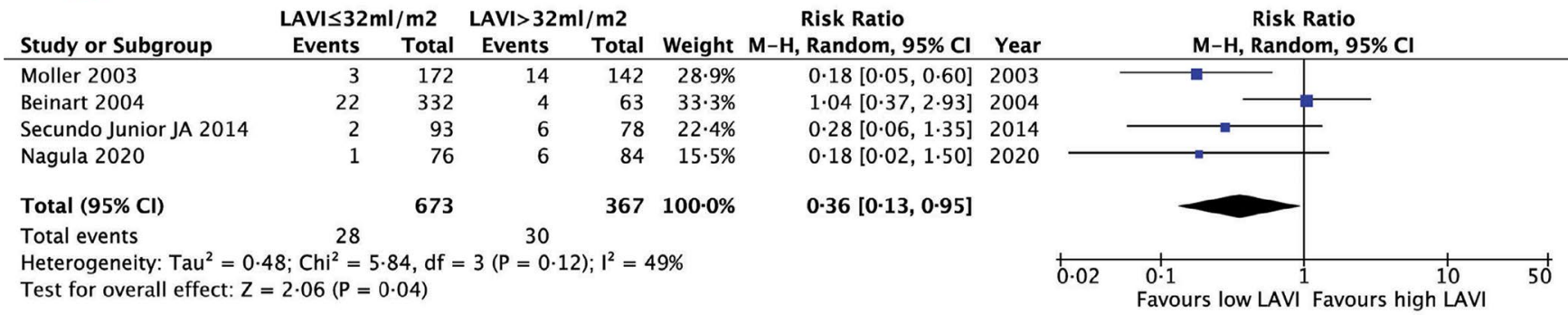

(c) Cardiogenic shock

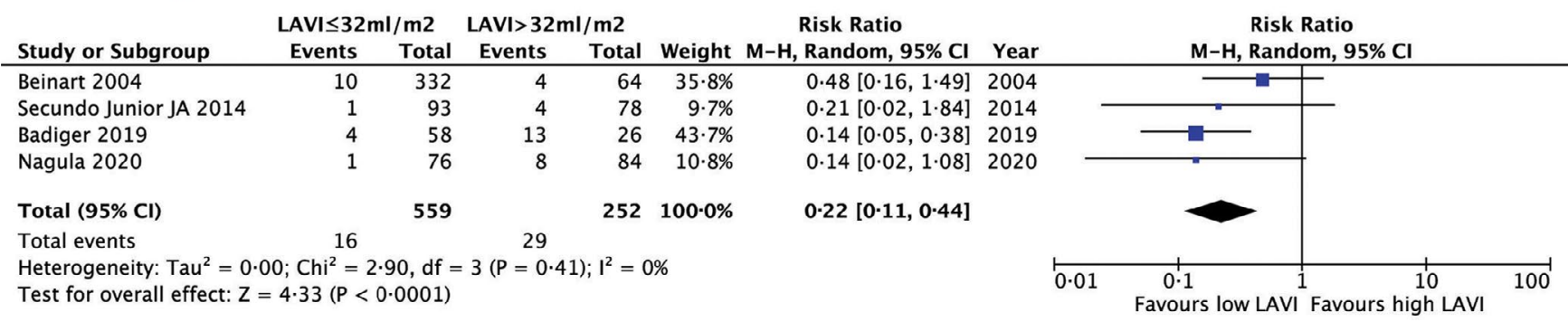

FIGURE 2 Risk ratios of clinical outcome in two groups of patients; (a) VT/VF; (b) AF; (c) cardiogenic shock

perpetual increases in pressures in response to those of the left ventricle (Bytyçi et al., 2019). As a result, LA pressure gets transmitted to the pulmonary venous system and causes pulmonary venous hypertension and eventually pulmonary arterial hypertension (Tossavainen et al., 2016). These changes in LV-LA and pulmonary circulation pressures should explain the significant worse clinical outcome we reported in patients with high LAVI compared to those with low LAVI. They also highlight the maintained LA function reserve in patients with low LAVI. While these pathophysiological LV-LA disturbances occur in all forms of LV disease, they tend to be exaggerated in patients presenting with ACS, since the acute loss of, even part, myocardial function in ventricles with, even, subclinical dysfunction are bound to cause acute rise of diastolic pressures and LA pressures, which themselves are known to increase the risk of ventricular arrhythmias (Appleton et al., 1993; Bytyçi et al., 2020; Gunasekaran et al., 2012; Nagarajarao et al., 2008), irrespective of the severity of coronary disease. Our findings also support this concept having shown that patients with high LAVI are bound to have worse diastolic function, and more prevalent multivessel coronary disease with its impact on overall LV function.
Furthermore, our results demonstrate that LA enlargement was associated with comorbidities such as hypertension, diabetes and previous ACS, which are known factors that impair LV diastolic function and raise its filling pressures (Anavekar et al., 2004; Foley et al., 1998). This may explain the relationship of higher prevalence of Killip and significant mitral regurgitation rate with their known clinical effects in patients with higher LAVI compared to those with low LAVI.

\section{3 | Limitations}

This analysis is based on the published data since 2003 that used a LAVI cut-off value of $32 \mathrm{ml} / \mathrm{m}^{2}$ and the recently published cut-off value of $34 \mathrm{ml} / \mathrm{m}^{2}$ according to recent guidelines. We did not have any data on the impact of changes in LAVI with treatment on clinical outcome, which could have altered our conclusion. We believe that the published data, which we identified and analysed, are collected based on conventional guidelines and the investigators adhered to conventionally used protocols. 


\section{4 | Clinical implications}

In patients presenting with ACS, baseline measurement of LAVI in addition to conventional echocardiographic measurements of left and right ventricles may help to stratify patients at higher risk for acute adverse events from those at low risk, during follow-up. Patients presenting with Doppler echocardiographic markers of raised LA pressure should receive optimum pressure off-loading therapy in order to maintain optimum myocardial protection and avoid related complications. Echocardiography is a unique bedside investigation for these patients and does not need any special preparation or patient transportation to a special imaging unit.

\section{5 | CONCLUSIONS}

Increased LAVI is an independent predictor of outcome in patients presenting with ACS. The assessment of LA volume index in these patients in daily practice is important for better risk stratification and guidance towards optimum clinical management.

\subsection{CONFLICT OF INTEREST}

The authors have no conflict of interest to declare.

\section{2 | AUTHOR'S CONTRIBUTION}

A.A., I.B. and M.Y.H. designed and drafted the article. A.A., F.S.B. and A.B.D collected and analysed the data. I.B. and M.Y.H. interpreted the data and critically revised the article.

\section{ORCID}

Ibadete Bytyçi (iD https://orcid.org/0000-0002-8996-4257

\section{REFERENCES}

Abhayaratna, W. P., Seward, J. B., Appleton, C. P., Douglas, P. S., Oh, J. K., Tajik, A. J., \& Tsang, T. S. (2006). Left atrial size: Physiologic determinants and clinical applications. Journal of the American College of Cardiology, 47(12), 2357-2363. https://doi.org/10.1016/j. jacc. 2006.02.048

Alam, M., Witt, N., Nordlander, R., \& Samad, B. (2007). Detection of abnormal left ventricular function by Doppler tissue imaging in patients with a first myocardial infarction and showing normal function assessed by conventional echocardiography. European Journal of Echocardiography, 8(1), 37-41. https://doi.org/10.1016/j.euje.2005.12.012

Anavekar, N. S., McMurray, J. J., Velazquez, E. J., Solomon, S. D. Køber, L., Rouleau, J. L., White, H. D., Nordlander, R., Maggioni, A., Dickstein, K., Zelenkofske, S., Leimberger, J. D., Califf, R. M., \& Pfeffer, M. A. (2004). Relation between renal dysfunction and cardiovascular outcomes after myocardial infarction. New England Journal of Medicine, 351(13), 1285-1295. https://doi.org/10.1056/ NEJMoa041365

Antoni, M. L., ten Brinke, E. A., Atary, J. Z., Marsan, N. A., Holman, E. R., Schalij, M. J., Bax, J. J., \& Delgado, V. (2011). Left atrial strain is related to adverse events in patients after acute myocardial infarction treated with primary percutaneous coronary intervention. Heart, 97(16), 1332-1337. https://doi.org/10.1136/ hrt.2011.227678

Appleton, C. P., Galloway, J. M., Gonzalez, M. S., Gaballa, M., \& Basnight, M. A. (1993). Estimation of left-ventricular filling pressure using 2-dimensional and Doppler- echocardiography in adult patients with cardiac disease. Additional value of analyzing left atrial size, left atrial ejection fraction and the difference in duration of pulmonary venous and mitral flow velocity at atrial contraction. Journal of the American College of Cardiology, 22, 1972-1982.

Badiger, S. (2019). Left atrial volume index: As a predictor of early in-hospital major adverse cardiovascular events in acute coronary syndrome. Journal of Clinical \& Diagnostic Research., 13, 26-29. https:// doi.org/10.7860/JCDR/2019/40552.12819

Basnight, M. A., Gonzalez, M. S., Kershenovich, S. C., \& Appleton, C. P. (1991). Pulmonary venous flow velocity: Relation to hemodynamics, mitral flow velocity and left atrial volume, and ejection fraction. Journal of the American Society of Echocardiography, 4(6), 547-558. https://doi.org/10.1016/S0894-7317(14)80213-7

Beinart, R., Boyko, V., Schwammenthal, E., Kuperstein, R., Sagie, A., Hod, H., Matetzky, S., Behar, S., Eldar, M., \& Feinberg, M. S. (2004). Longterm prognostic significance of left atrial volume in acute myocardial infarction. Journal of the American College of Cardiology, 44(2), 327334. https://doi.org/10.1016/j.jacc.2004.03.062

Bytyçi, I., \& Bajraktari, G. (2016). Left atrial changes in early stages of heart failure with preserved ejection fraction. Echocardiography, 33(10), 1479-1487.

Bytyçi, I., Bajraktari, G., \& Henein, M. Y. (2020). Left atrial volume index predicts response to cardiac resynchronisation therapy: A systematic review and meta-analysis. Archives of Medical Science, https:// doi.org/10.5114/aoms.2019.91511.

Bytyçi, I., Bajraktari, G., Lindqvist, P., \& Henein, M. Y. (2019). Compromised left atrial function and increased size predict raised cavity pressure: A systematic review and meta-analysis. Clinical Physiology and Functional Imaging, 39(5), 297-307. https://doi. org/10.1111/cpf.12587

Cho, J. H., Kim, S. H., Kim, C. H., Park, J. Y., Choi, S., Yun, M. H., Kim, D. H., Mun, J. H., Kim, J. Y., Yoon, H. J., Kim, K. H., \& Jeong, M. H. (2012). Prognostic value of left atrium remodeling after primary percutaneous coronary intervention in patients with ST elevation acute myocardial infarction. Journal of Korean Medical Science, 27(3), 236-242. https://doi.org/10.3346/jkms.2012.27.3.236

Cordeiro, F., Silva Mateus, P., Leão, S., Moz, M., Trigo, J., Ferreira, C., Carvalho, S. S., Ferreira, A., \& Moreira, J. I. (2018). Left atrial volume index: Can it provide additional prognostic information in ST-segment elevation myocardial infarction treated with primary percutaneous coronary intervention? Revista Portuguesa De Cardiologia, 37(10), 799-807. https://doi.org/10.1016/j. repc.2018.01.012

Dokainish, H., Zoghbi, W. A., Lakkis, N. M., Ambriz, E., Patel, R., Quinones, M. A., \& Nagueh, S. F. (2005). Incremental predictive power of B-type natriuretic peptide and tissue Doppler echocardiography in the prognosis of patients with congestive heart failure. Journal of the American College of Cardiology, 45(8), 1223-1226. https://doi.org/10.1016/j. jacc.2005.01.025

Foley, R. N., Parfrey, P. S., \& Sarnak, M. J. (1998). Clinical epidemiology of cardiovascular disease in chronic renal disease. American Journal of Kidney Diseases, 32(5), S112-S119. https://doi.org/10.1053/ ajkd.1998.v32.pm9820470

Gunasekaran, R., Maskon, O., Hassan, H. H., Safian, N., \& Sakthiswary, R. (2012). Left atrial volume index is an independent predictor of major adverse cardiovascular events in acute coronary syndrome. Canadian Journal of Cardiology, 28(5), 561-566. https://doi.org/10.1016/j. cjca.2012.02.015 
Higgins, J. P. T., Green, S. (eds) (2009). Cochrane handbook for systematic reviews of interventions version 5.0.2. The Cochrane Collaboration [updated September 2009].

Higgins, J. P., Thompson, S. G., Deeks, J. J., \& Altman, D. G. (2003). Measuring inconsistency in meta analyses. BMJ, 327, 557-560. https://doi.org/10.1136/bmj.327.7414.557

Hillis, G. S., Møller, J. E., Pellikka, P. A., Gersh, B. J., Wright, R. S., Ommen, S. R., Reeder, G. S., \& Oh, J. K. (2004). Noninvasive estimation of left ventricular filling pressure by $\mathrm{e} / \mathrm{e}^{\prime}$ is a powerful predictor of survival after acute myocardial infarction. Journal of the American College of Cardiology, 43, 360-367. https://doi.org/10.1016/j.jacc.2003.07.044

Hozo, S. P., Djulbegovic, B., \& Hozo, I. (2005). Estimating the mean and variance from the median, range, and the size of a sample. BMC Medical ResearchMethodology,5(1),13.https://doi.org/10.1186/1471-2288-5-13

Meris, A., Amigoni, M., Uno, H., Thune, J. J., Verma, A., Køber, L., Bourgoun, M., McMurray, J. J., Velazquez, E. J., Maggioni, A. P., Ghali, J., Arnold, J. M. O., Zelenkofske, S., Pfeffer, M. A., \& Solomon, S. D. (2009). Left atrial remodelling in patients with myocardial infarction complicated by heart failure, left ventricular dysfunction, or both: The VALIANT Echo study. European Heart Journal, 30(1), 56-65. https://doi.org/10.1093/eurheartj/ehn499

Moher D., Liberati A., Tetzlaff J., Altman D. G., Group P. (2009). Preferred reporting items for systematic reviews and meta-analyses: The PRISMA statement. BMJ, 339(1), b2535. https://doi.org/10.1136/bmj.b2535

Moller, J. E., Hillis, G. S., Oh, J. K., Seward, J. B., Reeder, G. S., Wright, R. S., Park, S. W., Bailey, K. R., \& Pellikka, P. A. (2003). Left atrial volume: A powerful predictor of survival after acute myocardial infarction. Circulation, 107(17), 2207-2212. https://doi.org/10.1161/01. CIR.0000066318.21784.43

Morton, S. C., Adams, J. L., Suttorp, M. J., \& Shekelle, P. G. (2004). Metaregression Approaches. In Why What, \& When, and How? Agency for Healthcare Research and Quality (US). Report No.: 04-0033.

Moss, A. J. (1984). Update of postinfarction-risk stratification: Physiologic variables. Annals of the New York Academy of Sciences, 427(1), 280285. https://doi.org/10.1111/j.1749-6632.1984.tb20790.x

Nagarajarao, H. S., Penman, A. D., Taylor, H. A., Mosley, T. H., Butler, K., Skelton, T. N., Samdarshi, T. E., Aru, G., \& Fox, E. R. (2008). The predictive value of left atrial size for incident ischemic stroke and all-cause mortality in African Americans: The Atherosclerosis Risk In Communities (ARIC) study. Stroke, 39(10), 2701-2706. https://doi. org/10.1161/STROKEAHA.108.515221

Nagula, P., Venkata Yerrabandi, S. R., Otikunta, A. N., \& Karumuri, S. (2020). A clinical study of prognostic significance of left atrial volume index in patients with acute coronary syndrome. Journal of Indian College of Cardiology, 9(4), 186-192. https://doi.org/10.4103/ JICC.JICC_39_19

Nijland, F., Kamp, O., Karreman, A. J., van Eenige, M. J., \& Visser, C. A. (1997). Prognostic implications of restrictive left ventricular filling in acute myocardial infarction: A serial doppler echocardiographic study. 11To discuss this article on-line, visit the ACC Home Page at www.acc.org/membersand click on the JACC Forum. Journal of the American College of Cardiology, 30(7), 1618-1624. https://doi. org/10.1016/S0735-1097(97)00369-0
Patel, D. A., Lavie, C. J., Milani, R. V., \& Ventura, H. O. (2011). Left atrial volume index predictive of mortality independent of left ventricular geometry in a large clinical cohort with preserved ejection fraction. Mayo Clinic Proceedings, 86(8), 730-737. https://doi.org/10.4065/ mcp.2010.0682

Sakaguchi, E., Yamada, A., Sugimoto, K., Ito, Y., Shiino, K., Takada, K., Iwase, M., \& Ozaki, Y. (2011). Prognostic value of left atrial volume index in patents with first acute myocardial infarction. European Journal of Echocardiography, 12(6), 440-444. https://doi. org/10.1093/ejechocard/jer058

Salehi, R., Samadikhah J., Azarfarin R., Goldust M.. Effect of left atrium volume on patients' prognosis following acute myocardial infarction. PJBS, 2013, 16(24):1936-1942.

Secundo Junior, J. A., Santos, M. A., Faro, G. B., Soares, C. B., Silva, A. M., Secundo, P. F., Teixeira, C. K. C., Oliveira, J. L. M., Barreto Filho, J. A. S., \& Sousa, A. C. S. (2014). Left atrial volume index and prediction of events in acute coronary syndrome: Solar Registry. Arquivos Brasileiros De Cardiologia, 103(4), 282-291. https://doi.org/10.5935/ abc. 20140122

Sestili, A., Coletta, C., Manno, V., Perna, S., Renzi, M., Romano, P., Ricci, R., \& Ceci, V. (2007). Restrictive mitral inflow pattern is a strong independent predictor of lack of viable myocardium after a first acute myocardial infarction. European Journal of Echocardiography, 8, 332340. https://doi.org/10.1016/j.euje.2006.06.005

Tossavainen, E., Henein, M. Y., Grönlund, C., \& Lindqvist, P. (2016). Left atrial intrinsic strain rate correcting for pulmonary wedge pressure is accurate in estimating pulmonary vascular resistance in breathless patients. Echocardiography, 33(8), 1156-1165.

Tsang, T. S., Barnes, M. E., Gersh, B. J., Bailey, K. R., \& Seward, J. B. (2002). Left atrial volume as a morphophysiologic expression of left ventricular diastolic dysfunction and relation to cardiovascular risk burden. American Journal of Cardiology, 90(12), 1284-1289. https:// doi.org/10.1016/S0002-9149(02)02864-3

Zeng, X., Zhang, Y., Kwong, J. S., Zhang, C., Li, S., Sun, F., Niu, Y., \& Du, L. (2015). The methodological quality assessment tools for preclinical and clinical studies, systematic review and meta-analysis, and clinical practice guideline: A systematic review. Journal of Evidence-Based Medicine, 8(1), 2-10. https://doi.org/10.1111/jebm.12141

\section{SUPPORTING INFORMATION}

Additional supporting information may be found online in the Supporting Information section.

How to cite this article: Ahmeti A, Bytyçi FS, BieleckaDabrowa A, Bytyçi I, Henein MY. Prognostic value of left atrial volume index in acute coronary syndrome: A systematic review and meta-analysis. Clin Physiol Funct Imaging. 2021;41:128-135. https://doi.org/10.1111/cpf.12689 